\title{
Asiaticoside inhibits epithelial-mesenchymal transition and stem cell-like properties of pancreatic cancer PANC-1 cells by blocking the activation of p65 and p38MAPK
}

\author{
Yonggang He ${ }^{\#}$, Xuehui Peng ${ }^{\#}$, Lu Zheng, Yichen Tang, Jing Li, Xiaobing Huang \\ Department of Hepatobiliary Surgery, The Second Affiliated Hospital of Army Medical University, Chongqing, China \\ Contributions: (I) Conception and design: J Li, X Huang; (II) Administrative support: J Li, X Huang; (III) Provision of study materials or patients: Y \\ He, X Peng; (IV) Collection and assembly of data: Y He, X Peng; (V) Data analysis and interpretation: L Zheng, Y Tang; (VI) Manuscript writing: \\ All authors; (VII) Final approval of manuscript: All authors. \\ \#These authors contributed equally to this work. \\ Correspondence to: Jing Li; Xiaobing Huang. Department of Hepatobiliary Surgery, The Second Affiliated Hospital of Army Medical University, No. \\ 183, Xinqiaozheng Street, Shapingba District, Chongqing 400037, China. Email: heyong202009@126.com; hongbeihan@yeah.net.
}

Background: To analyze the inhibitory effects of Asiaticoside (ATS) on the epithelial-mesenchymal transition (EMT) and stem cell-like properties of a pancreatic cancer cell line (PANC-1) by blocking the activation of p65 and p38 mitogen-activated protein kinase (p38MAPK).

Methods: ATS concentrations were set at $0,10,25$, and $50 \mu \mathrm{mol} / \mathrm{L}$. The survival rate of PANC- 1 cells in each group was detected by CCK-8, and CD133 and CD44 positive cells were detected by flow cytometry. The levels of Ki67 and proliferating cell nuclear antigen (PCNA) mRNA were detected by RT-PCR. The expression of E-cadherin, N-cadherin, vimentin, sex-determining region Y-box2 (SOX2), and octamerbinding transcription factor 4 (OCT4) proteins, and the phosphorylation levels of p65 and p38MAPK were detected by western blot. Nude mouse xenograft models of the tumor were established by subcutaneous injection of PANC-1 cells $\left(1 \times 10^{6}-1 \times 10^{8} / \mathrm{mL}\right)$, and they were randomly divided into the control group $(0 \mathrm{mg} / \mathrm{kg})$, and low-dose, medium-dose, and high-dose ATS groups $(2.5,5,10 \mathrm{mg} / \mathrm{kg})$. Apoptosis in xenograft tissue was detected by TUNEL, and the expression of vimentin and SOX2 proteins was detected by immunohistochemistry.

Results: As the ATS concentration increased to $25 \mu \mathrm{mol} / \mathrm{L}$, cell survival rate, levels of Ki67 and PCNA mRNA, expression of N-cadherin, vimentin, SOX2, OCT4, p-p65/p65, and p-p38MAPK/p38MAPK proteins, and the proportions of $\mathrm{CD}_{4} 4^{+}$and $\mathrm{CD} 133^{+}$positive cells significantly decreased $(\mathrm{P}<0.05)$, while the expression of $\mathrm{E}$-cadherin protein significantly increased $(\mathrm{P}<0.05)$. The results of tumor formation in nude mice showed that with the increase of ATS concentration, at $5 \mathrm{mg} / \mathrm{kg}$ the volume of the xenograft significantly decreased $(\mathrm{P}<0.05)$, the apoptosis rate significantly increased $(\mathrm{P}<0.05)$, and positive expression rates of vimentin and SOX2 proteins significantly decreased $(\mathrm{P}<0.05)$.

Conclusions: ATS may inhibit the proliferation, EMT, and stem cell-like properties of pancreatic cancer cells by blocking the phosphorylation of p38MAPK and nuclear factor- $\kappa \mathrm{B}(\mathrm{NF}-\kappa \mathrm{B}) / \mathrm{p} 65$ in PANC-1 cells.

Keywords: Asiaticoside (ATS); epithelial-mesenchymal transition (EMT); pancreatic cancer; stem cells

Submitted Oct 15, 2020. Accepted for publication Dec 16, 2020.

doi: 10.21037/jgo-20-533

View this article at: http://dx.doi.org/10.21037/jgo-20-533

(C) Journal of Gastrointestinal Oncology. All rights reserved. 


\section{Introduction}

Pancreatic cancer is a common tumor of the digestive system with a high degree of malignancy and a poor prognosis. The main clinical approach is surgery, supplemented by comprehensive treatment measures of radiotherapy and chemotherapy (1). Patients with pancreatic cancer often do not show typical symptoms in the early stage, so the detection rate is low, and they have often developed to the middle and late stages when they go to the doctor. The rate of surgical resection is low, and the rate of surgical recurrence and metastasis is high. Novel therapies such as FOLFIRINOX, a therapy combination including folinic acid, 5-fluoruracil, irinotecan and oxaliplatin, have significantly improved the treatment. However, median survival for advanced or metastatic patients was less than one and a half years even with such therapies (2). It is of great clinical significance to analyze the mechanism of the malignant progression of pancreatic cancer and find new effective drugs to assist clinical treatment. The epithelialmesenchymal transition (EMT) is the basis of tumor cell invasion and migration, and plays an important role in the occurrence and metastasis of pancreatic cancer (3). Recent studies have shown that EMT is related to cancer stem cell-like characteristics, participates in the self-renewal and differentiation of cancer stem cell-like cells, and plays an important role in tumor occurrence, invasion, metastasis, and recurrence (4). Asiaticoside (ATS) is extracted from the Apiaceae plant Centella asiatica and has antioxidative, antifibrotic, and antineoplastic actions (5). Studies have shown that ATS can inhibit the proliferation and invasion of multiple myeloma cells, and induce tumor cell apoptosis (6), but its effect on the stem-like characteristics of pancreatic cancer cells is still unclear. Therefore, this study explored the effect of ATS on EMT and stem cell-like characteristics of pancreatic cancer cell line (PANC-1) cells, aiming to provide a reference for the clinical treatment of pancreatic cancer. We present the following article in accordance with the ARRIVE reporting checklist (available at http://dx.doi. org/10.21037/jgo-20-533).

\section{Methods}

\section{Instruments and reagents}

The $\mathrm{CO}_{2}$ incubator and automatic microplate reader were purchased from Thermo Scientific; flow cytometer was purchased from FASCAN Becton Dickison, USA; vernier calipers (precision $0.1 \mathrm{~mm}, \mathrm{EC}-200$ ) were purchased from Chengdu Measuring Tool \& Cutting Tool Co., Ltd.; pancreatic cancer PANC-1 cells were purchased from the cell bank of the Shanghai Chinese Academy of Sciences; ATS was purchased from Guangxi Changzhou Natural Products Development Co., Ltd., with a purity of >95\%; RPMI 1640 medium and mycoplasma-free fetal bovine serum were purchased from Zhejiang Tianhang Biotechnology Co., Ltd.; CCK-8 detection kit and TUNEL tissue apoptosis detection kit were purchased from Shenyang Wanlei Biotechnology Co., Ltd.; $\beta$-actin monoclonal antibody was purchased from Beijing Soleibao Technology Co., Ltd.; CD133-PE and CD44-FITC antibodies were purchased from Miltenyi Biotec, Germany; rabbit anti-human E-cadherin, $\mathrm{N}$-cadherin, vimentin, and $\mathrm{p} 65, \mathrm{p}-\mathrm{p} 65, \mathrm{p} 38$ mitogen-activated protein kinase (p38MAPK), p-p38MAPK monoclonal antibodies, were purchased from Santa Cruz, USA; horseradish peroxidase (HRP) labeled goat anti-rabbit IgG was purchased from DAKO, Denmark.

We also purchased 40 male BALB/C nude mice, aged 4-6 weeks, weighing 17-22 g from Beijing Weitong Lihua Laboratory Animal Technology Co., Ltd. [animal license number SCXK (Beijing) 2016-0006]. The in vivo experiments were carried out in the Weitong Lihua Laboratory Animal Technology Co., Ltd according to Chinese National Guidelines (GB/T 35892-20181).

\section{Cell culture and drug treatment}

PANC- 1 cells (about $1.5 \times 10^{4}$ in a flask) were cultured in RPMI 1640 medium containing $10 \%$ fetal bovine serum, incubated overnight at $37{ }^{\circ} \mathrm{C}$ in $5 \% \mathrm{CO}_{2}$; the medium was changed the next day, and subculture was started after cell fusion reached $\geq 80 \%$. Cells in the logarithmic growth phase were used to make a single-cell suspension $\left(5 \times 10^{4} / \mathrm{mL}\right)$, and cultured overnight. Next, $100 \mu \mathrm{L}$ of different concentrations of ATS (final concentration 0, 0.5, 1, 2.5, 5, 10, 25, 50, 100, 200,300 , and $400 \mu \mathrm{mol} / \mathrm{L}$ ) was added, followed by incubation for $24 \mathrm{~h}$. The culture medium was discarded, $10 \mu \mathrm{L}$ of CCK- 8 solution was added to each well, and there was a further $4 \mathrm{~h}$ of incubation. Finally, absorbance at $450 \mathrm{~nm}$ wavelength was detected, and the cell survival rate was calculated. Setting the ATS low-dose group as $10 \mu \mathrm{mol} / \mathrm{L}$, the medium-dose $(25 \mu \mathrm{mol} / \mathrm{L})$, high-dose $(50 \mu \mathrm{mol} / \mathrm{L})$, and control $(0 \mu \mathrm{mol} / \mathrm{L})$ groups were established. For the wound enclosure test, cells of $80 \%$ confluence were scratched with a $200 \mu \mathrm{L}$ tip, and observed at 0 and $24 \mathrm{~h}$ respectively. For transwell, 50,000 cells were seeded in the $6 \mathrm{mg} / \mathrm{L}$ Matrigel 
pretreated upper chamber of the Transwell, with DMEM containing $0.1 \%$ FBS. The lower chamber was added with normal culture medium. After $24 \mathrm{~h}$ the cells were stained with hematoxylin and observed under a microscope.

\section{RT-PCR detection of proliferation markers Ki67 and PCNA mRNA levels}

Each group of cells incubated with the corresponding concentration of ATS for $24 \mathrm{~h}$ was used to extract total RNA by the Trizol method. Next, the RNA concentration and purity were determined by electrophoresis, and the cDNA was synthesized by reverse transcription (RT), which was then used to perform RT-PCR reaction, and detect $\mathrm{Ki} 67$ mRNA (forward primer: 5 '-CTTTGGGTGCGACTTGACGA-3', reverse primer: 5'-TTCTGCCATTACGTCCAGCG-3') and Proliferating Cell Nuclear Antigen (PCNA) (forward primer: 5'-AGGGCTGAAGATAATGCTGATA-3', reverse primer: 5'- CTCATTCATCTCTATGGTCACAG-3'). Glyceraldehyde-3-phosphate dehydrogenase (GAPDH) was used as the internal reference, and the relative expression level was calculated using $2^{-\Delta \Delta \mathrm{Ct}}$.

\section{Flow cytometric detection of $C D 133^{+}$and $C D 44^{+}$positive cells}

Each group of cells incubated with the corresponding concentration of ATS for $24 \mathrm{~h}$ was suspended with trypsin, and the cells were collected by centrifugation (400 $\mathrm{g}$ for $5 \mathrm{~min}$ ). The supernatant was discarded, the cells were resuspended in phosphate-buffered saline (PBS), and their concentration adjusted to $1 \times 10^{6} \mathrm{~mL}$. Thereafter, CD133$\mathrm{PE}$ and CD44-FITC (diluted 1:100) antibodies were added, before incubation for $30 \mathrm{~min}$ at $4{ }^{\circ} \mathrm{C}$, followed by washing twice with PBS, centrifugation (1,000 rpm, $5 \mathrm{~min}$ ), resuspension in $200 \mu \mathrm{L} \mathrm{PBS}$, and analyzed by flow cytometry.

\section{Western blot detection of phosphorylated protein expression of E-cadherin, N-cadherin, vimentin, SOX2, OCT4, p65 and $\mathrm{p} 38 \mathrm{MAPK}$}

Each group of cells incubated with the corresponding concentration of ATS for $24 \mathrm{~h}$ was used to extract the total cell protein with cell lysate, and the protein concentration was determined by the quinolinic acid method. The protein was used for SDS-PAGE gel electrophoresis, and the membrane was electro-transferred to a polyvinylidene fluoride membrane, which was blocked for $2 \mathrm{~h}$ at room temperature, washed with membrane washing buffer, before adding the primary antibodies (E-cadherin, $\mathrm{N}$-cadherin, Vimentin, SOX2, OCT4, p65, p-p65, p38MAPK, and p-p38MAPK and beta-actin), and incubating overnight at $4{ }^{\circ} \mathrm{C}$. The membrane was washed with membrane washing buffer and the secondary antibody was added to incubate for $2 \mathrm{~h}$ at room temperature. Finally, electrochemiluminescence was used for imaging, with $\beta$-actin as the internal reference, and a gel imaging system was used to analyze the strength of the contrast band.

\section{Establishment of PANC-1 nude mouse xenograft tumor model}

After 7 days of acclimatization, the nude mice were randomly divided into a control group, and ATS low-dose, medium-dose, and high-dose groups. All nude mice were injected subcutaneously with $0.1 \mathrm{~mL}$ PANC- 1 cells $\left(1 \times 10^{6}-\right.$ $1 \times 10^{8} / \mathrm{mL}$ ) to establish a nude mouse xenograft tumor model. A nude mouse with visible subcutaneous tumor formation was regarded as a successful model. When the tumor volume reached $\approx 100 \mathrm{~mm}^{3}$, the ATS low-, medium-, and high-dose groups were intraperitoneally injected with $2.5,5$, and $10 \mathrm{mg} / \mathrm{kg}$ ATS, and the control group was injected with the same volume of normal saline. At 30 days after the injection, the nude mice were killed humanely, the tumor tissue was removed, and the volume of tumor in each group was measured.

\section{TUNEL method to detect cell apoptosis in tumor tissue}

The resected tumor tissue was placed in a $4 \%$ paraformaldehyde solution for fixation, routine sectioning, and then deparaffinizing to water. Proteinase K working solution was added for antigen retrieval, and samples were fixed at room temperature for $15-30 \mathrm{~min}$. Next, $50 \mu \mathrm{L}$ of $3 \% \mathrm{H}_{2} \mathrm{O}_{2}$ was added, incubated at room temperature for $10 \mathrm{~min}$, then $50 \mu \mathrm{L}$ TUNEL reaction solution was added, further incubated at $37^{\circ} \mathrm{C}$ in the dark for $60 \mathrm{mins}$, and finally rinsed three times with PBS for 5 min each time. Then, $50 \mu \mathrm{L}$ peroxidase buffer solution was added, reacted at $37^{\circ} \mathrm{C}$ for $30 \mathrm{~min}$, rinsed three times with PBS, developed with $\mathrm{DAB}$, and staining was performed in strict accordance with the instructions of the TUNEL kit. 


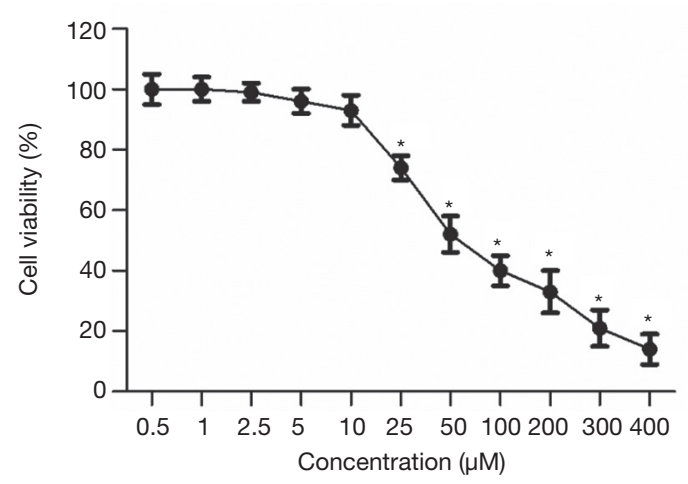

Figure 1 Effect of Asiaticoside (ATS) on the survival rate of PANC-1 cells indicated with CCK-8. Compared with the effect of $0 \mu \mathrm{mol} / \mathrm{L}$ ATS, ${ }^{*} \mathrm{P}<0.05$.

\section{Immunobistochemical method to detect the expression of VIMENTIN and SOX2 protein in transplanted tumor tissue}

Tumor tissue sections were deparaffinized to water in turn, then treated with $1.5 \% \mathrm{H}_{2} \mathrm{O}_{2}-\mathrm{CH}_{3} \mathrm{OH}$ solution at $37^{\circ} \mathrm{C}$ for $30 \mathrm{~min}$, blocked, and incubated at $37^{\circ} \mathrm{C}$ for $30 \mathrm{~min}$. Primary antibodies (vimentin and SOX2) were added respectively for 4 different sections and incubated overnight at $4{ }^{\circ} \mathrm{C}$. Next, a biotin-labeled secondary antibody was added and incubated at $37^{\circ} \mathrm{C}$ for another $30 \mathrm{~min}$, color developed with $\mathrm{DAB}$ and controlled under the microscope so that the secondary antibody was properly bonded. Finally, sections were stained with hematoxylin and cleared with xylene after sealing with neutral gum. The number of positive cells was counted under the microscope.

\section{Statistical analysis}

SPSS 17.0 software was used to analyze the obtained data, and the measurement data that met normality are expressed as mean \pm standard deviation $\left(\bar{x}_{ \pm \mathrm{S}}\right)$. Differences between groups were compared by one-way analysis of variance, and the difference between two groups was compared by Student-Newman-Keuls (SNK)-q. $\mathrm{P}<0.05$ indicated statistically significant difference.

\section{Results}

\section{Effects of ATS on the survival rate of PANC-1 cells}

The results of CCK-8 addition (Figure 1) showed that the inhibitory effect of ATS on PANC-1 cells was drug concentration-dependent. As the ATS concentration increased, when it reached $25 \mu \mathrm{mol} / \mathrm{L}$ the cell survival rate decreased significantly $(\mathrm{P}<0.05)$.

\section{Effect of ATS on the expression of PANC-1 cell proliferation-related genes and EMT-related proteins}

The RT-PCR results (Figure $2 A, B$ ) showed that with increasing ATS concentration when it was $25 \mu \mathrm{mol} / \mathrm{L}$, the cells' Ki67 and PCNA mRNA levels decreased significantly $(\mathrm{P}<0.05)$. Western blot results (Figure $2 C, D)$ showed that when the ATS concentration was $25 \mu \mathrm{mol} / \mathrm{L}$, the cells' E-cadherin protein expression increased significantly $(\mathrm{P}<0.05)$, while that of $\mathrm{N}$-cadherin and vimentin decreased significantly $(\mathrm{P}<0.05)$.

\section{Effect of ATS on $\mathrm{CD}_{4} 4^{+}$and $C D 133^{+}$positive cells, and SOX2, OCT4 protein expression}

The results of flow cytometry (Figure $3 A, B$ ) showed that when the ATS concentration was $25 \mu \mathrm{mol} / \mathrm{L}$, the proportions of $\mathrm{CD}_{4} 4^{+}$and $\mathrm{CD} 133^{+}$positive cells decreased significantly $(\mathrm{P}<0.05)$. Western blot results (Figure $3 C, D)$ showed that when the ATS concentration was $25 \mu \mathrm{mol} / \mathrm{L}$, the cells' SOX2 and OCT4 protein expressions decreased significantly $(\mathrm{P}<0.05)$.

\section{Effect of ATS on the phosphorylation of p65 and p38MAPK in PANC-1 cells}

Western blot results (Figure 4A) showed that when the ATS concentration was $25 \mu \mathrm{mol} / \mathrm{L}$, the cells' p-p65/p65 and p-p38MAPK/p38MAPK protein expressions decreased significantly (Figure $4 B, C, \mathrm{P}<0.05$ ). Then activators for nuclear factor- $\mathrm{\kappa B}(\mathrm{NF}-\kappa \mathrm{B})$ and $\mathrm{P} 38 \mathrm{MAPK}$ were employed to show the involvement of NF- $\mathrm{KB}$ and P38 MAPK. Both $\mathrm{NF}-\kappa \mathrm{B}$ activator RANKL $(10 \mathrm{ng} / \mathrm{mL})$ and P38 MAPK activator Asiatic acid $(4.6 \mathrm{mM})$ did not invert the decreased cell viability (Figure 4D). Then MAPK and EMT related proteins were tested (Figure 4E). RANKL and Asiatic acid activated $\mathrm{P} 65$ and $\mathrm{P} 38$ respectively (Figure $4 F, G, \mathrm{P}<0.05$ ). $\mathrm{E}$-cadherin was increased with ATS while decreased with both activators (Figure $4 H, \mathrm{P}<0.05$ ). $\mathrm{N}$-cadherin and Vimentin reduced with ATS was reverted with RANKL and Asiatic acid (Figure 4I, $\mathcal{F}, \mathrm{P}<0.05$ ). Similarly, ATS decreased SOX2 and OCT4 were also reverted with RANKL and Asiatic acid (Figure $4 K, L, \mathrm{P}<0.05$ ). ATS treatment inhibited 
A

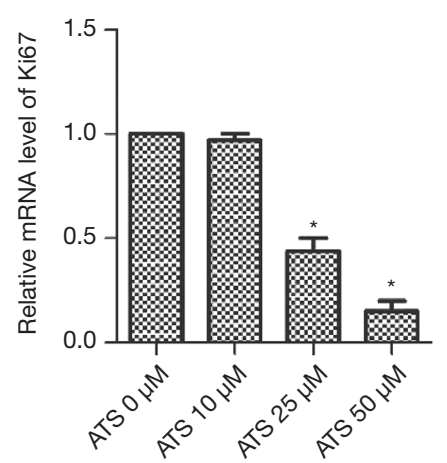

C

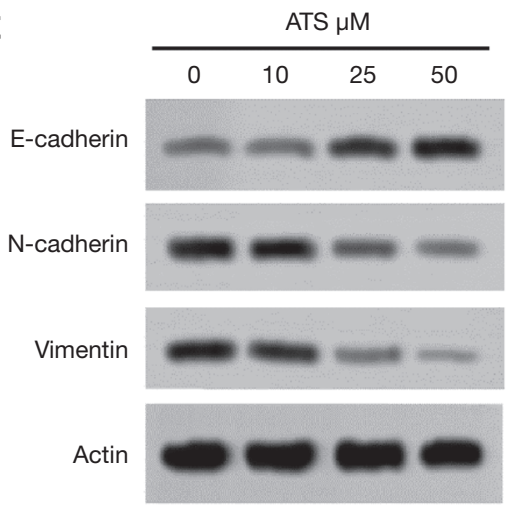

B
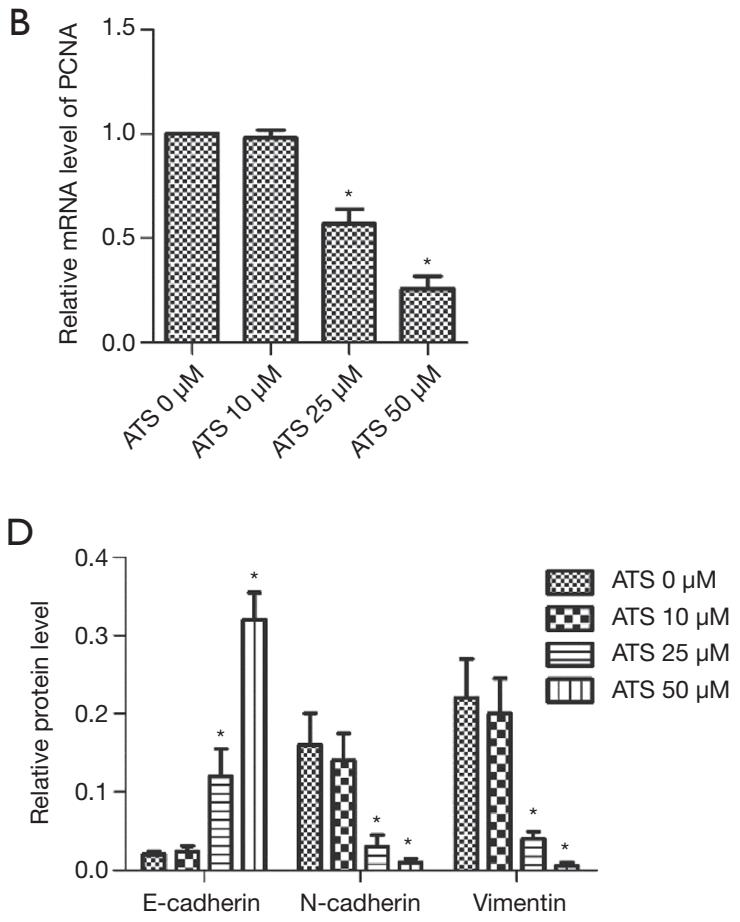

Figure 2 Effect of Asiaticoside (ATS) on the expression of pancreatic cancer cell line (PANC-1) cell proliferation-related genes and epithelial-mesenchymal transition (EMT)-related proteins. RT-PCR to detect the relative expression of (A) Ki67 mRNA and (B) PCNA mRNA. Western blot to detect (C) protein expression profiles and (D) to detect E-cadherin, N-cadherin and the relative expression of vimentin compared with the effect of $0 \mu \mathrm{mol} / \mathrm{L}$ ATS, ${ }^{*} \mathrm{P}<0.05$.

wound healing of PANC-1 cells, which was partly reverted with RANKL and Asiatic acid (Figure $4 M, \mathrm{P}<0.05$ ). A similar trend was observed in invasive cells tested with transwell (Figure $4 N, \mathrm{P}<0.05$ ). The results collectively indicated that ATS inhibited proliferation mobility and stemness of PANC-1 cells possibly through inactivating $\mathrm{NF}-\kappa \mathrm{B}$ and P38 MAPK.

\section{Effects of ATS on the growth, apoptosis, and expression of vimentin and SOX2 protein of transplanted tumor cells in nude mice}

The results of tumor formation in nude mice (Figure $5 A, B$ ) showed that when the ATS concentration was $5 \mathrm{mg} / \mathrm{kg}$ and $10 \mathrm{mg} / \mathrm{kg}$, the tumor's weight and volume decreased significantly $(\mathrm{P}<0.05)$. The TUNEL results (Figure 5C,D) showed that when the ATS concentration was $5 \mathrm{mg} /$ $\mathrm{kg}$, the cell apoptosis rate of the tumor tissue increased significantly $(\mathrm{P}<0.05)$. The results of immunohistochemistry
(Figure 5C,E,F) showed that the positive expression rates of vimentin and SOX2 proteins in tumor tissues significantly decreased $(\mathrm{P}<0.05)$.

\section{Discussion}

Pancreatic cancer is a highly aggressive malignant tumor with a poor prognosis, and no clinically effective treatment. ATS is a biologically effective active ingredient extracted from Centella asiatica that can inhibit the malignant behavior of some tumor cells (7), but its effect on pancreatic cancer cells is still unclear. Therefore, this study analyzed the effects of ATS on the EMT and stem cell-like characteristics of PANC-1 pancreatic cancer cells. In this study, the inhibitory effect of ATS on PANC-1 cells was concentration-dependent, and when the ATS concentration was $\geq 25 \mu \mathrm{mol} / \mathrm{L}$, not only the cell survival rate decreased significantly, but also the levels of Ki67 and PCNA mRNA decreased significantly. Both Ki67 and PCNA are tumor cell 


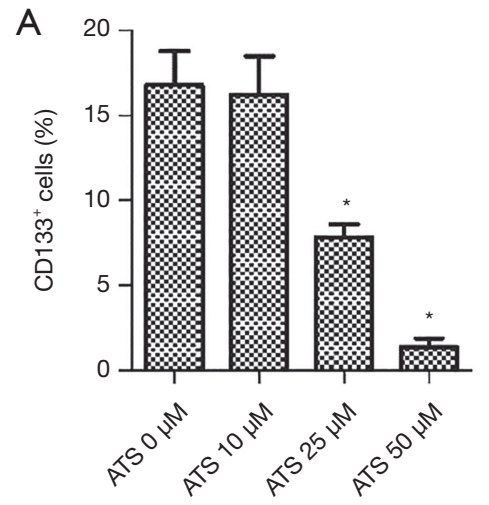

C

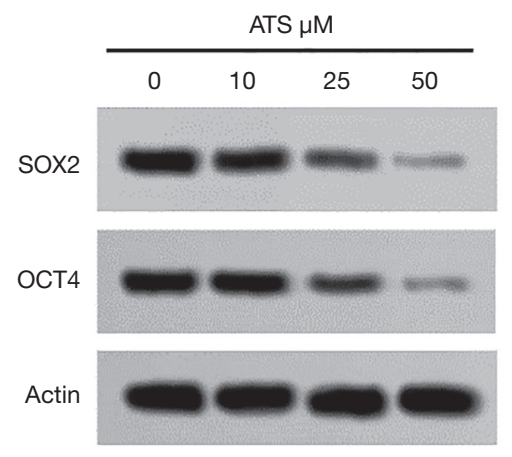

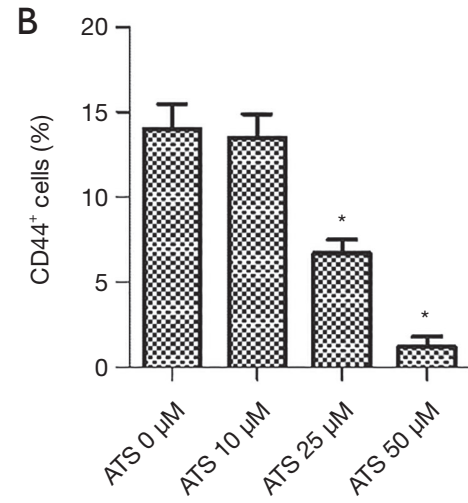

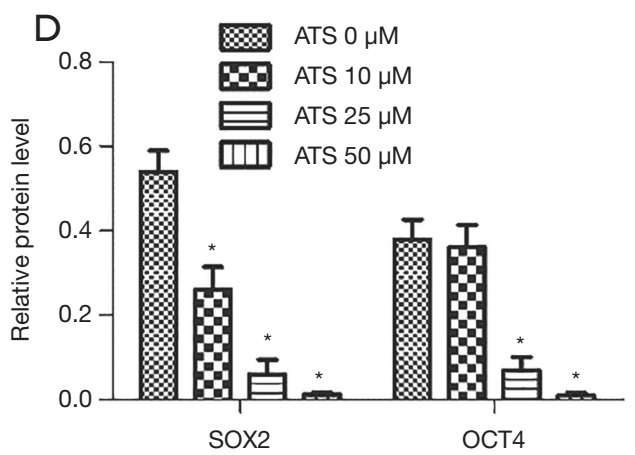

Figure 3 Effect of Asiaticoside (ATS) on $\mathrm{CD}_{4} 4^{+}$and $\mathrm{CD}_{133^{+}}$positive cells, and SOX2, OCT4 protein expression. Proportion of (A) CD133 ${ }^{+}$ positive cells and (B) CD44 $4^{+}$positive cells detected by flow cytometry; (C) protein expression profile detected by Western Blot; (D) relative expression levels of SOX2 and OCT4 detected by Western Blot; Compared with the effect of $0 \mu \mathrm{mol} / \mathrm{L}$ ATS, ${ }^{*} \mathrm{P}<0.05$.

proliferation-related proteins, and their levels change with cell mitosis. They are ideal markers of cell proliferation (8), and our results suggested that ATS can inhibit the proliferation of PANC-1 cells by decreasing the expression of proteins related to cell proliferation in a concentrationdependent manner.

EMT program is the key to malignant transformation across tumors. The survival of metastatic patients would be dramatically reduced (2), which was enabled with EMT. EMT promotes stemness, drug resistance and immune escape of tumor cells, and make the tumors impossible to be surgically removed. Targeting of EMT to prevent malignant transforming was pivotal for pancreatic cancer patients (3). AST was reported to inhibit TGF- $\beta$-induced EMT in in the human peritoneal mesothelial cell line HMrSV5 (9). On the other hand, AST inhibits Matrix metalloproteinase, hyaluronidase and elastase (10), all of which could degrade extracellular matrix to promote EMT. In this study, when the ATS concentration reached $25 \mu \mathrm{mol} / \mathrm{L}$, the cells' E-cadherin protein expression increased significantly, while that of $\mathrm{N}$-cadherin and vimentin decreased significantly. E-cadherin is a calcium-dependent epithelial marker protein that exists in almost all normal epithelial cells. It mediates adhesion between cells and plays an important role in tumor cell invasion and migration (11). N-cadherin, a calciumdependent cell surface adhesion molecule, also mediated the adhesion and migration of cancer cells, and promotes the malignant biological behavior of tumor cells (12). Vimentin is mainly expressed in mesenchymal cells and as a component of the cytoskeleton, it can regulate cell adhesion and promote tumor cell invasion and migration (13). Bulzico et al. showed that in adrenocortical carcinomas specimens the expression of E-cadherin protein is reduced or even absent, and the expression of $\mathrm{N}$-Cadherin and Vimentin protein is upregulated (14), which are signs of EMT in cancer cells, suggesting that ATS can decrease the expression of PANC-1 EMT-related proteins in a concentration-dependent manner to inhibit cell invasion and metastasis.

Cancer cells that undergo EMT could get stemness (4). 


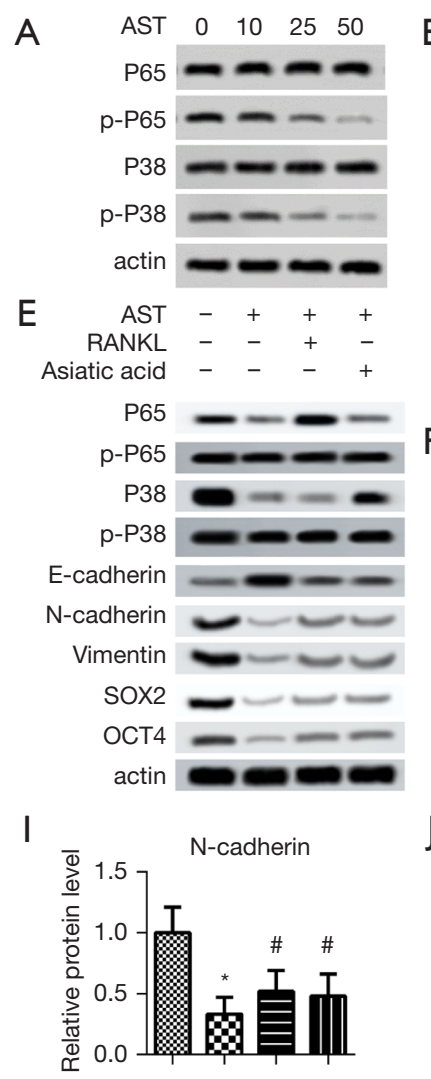

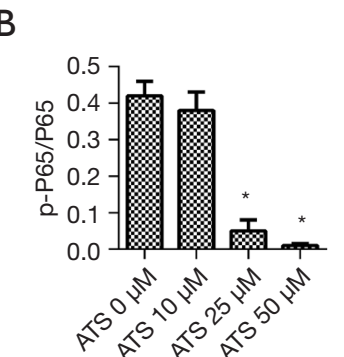

C

G

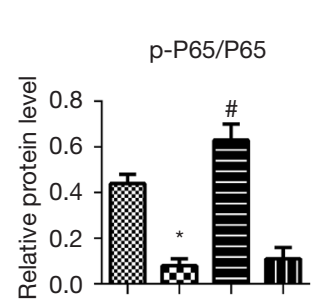

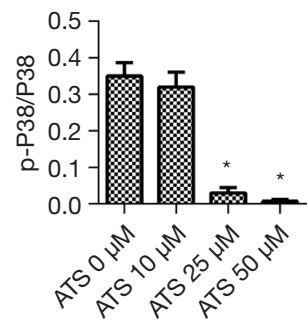

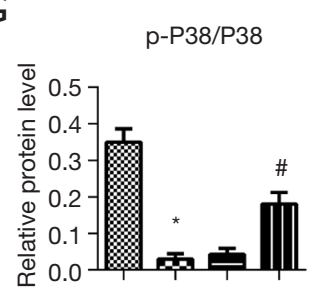

D

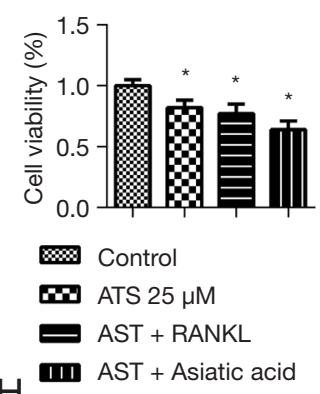

$\mathrm{H}$

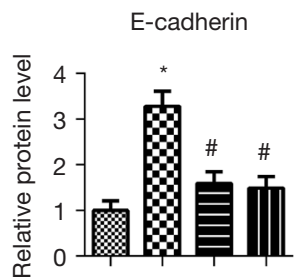

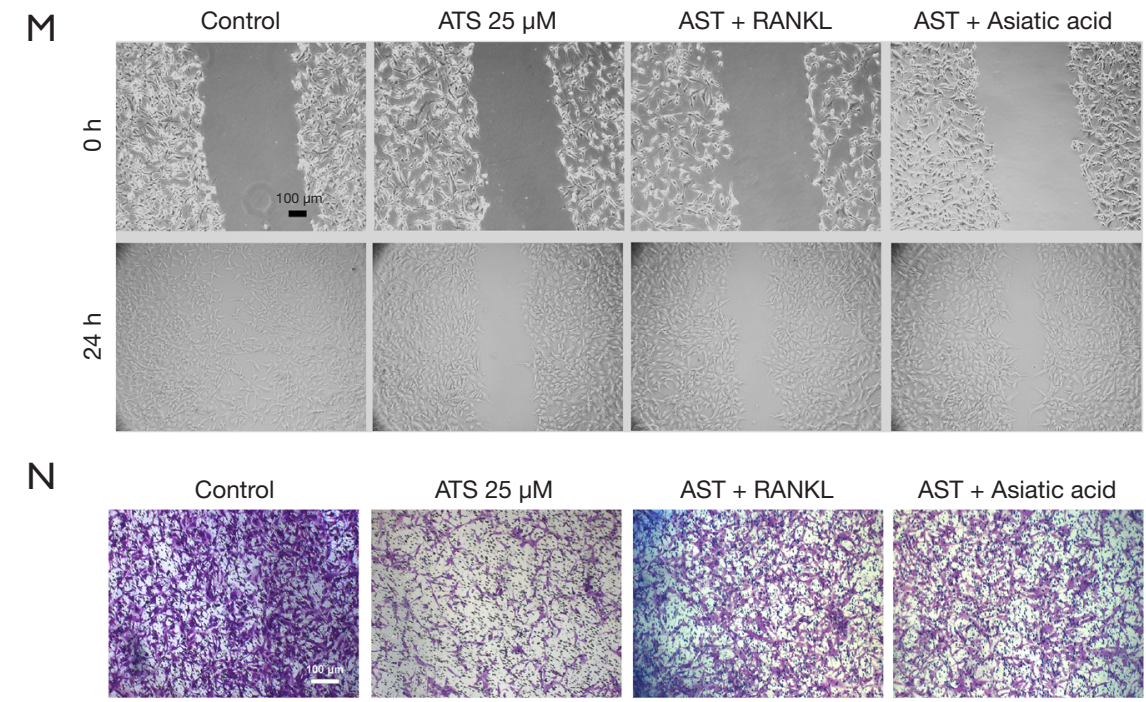
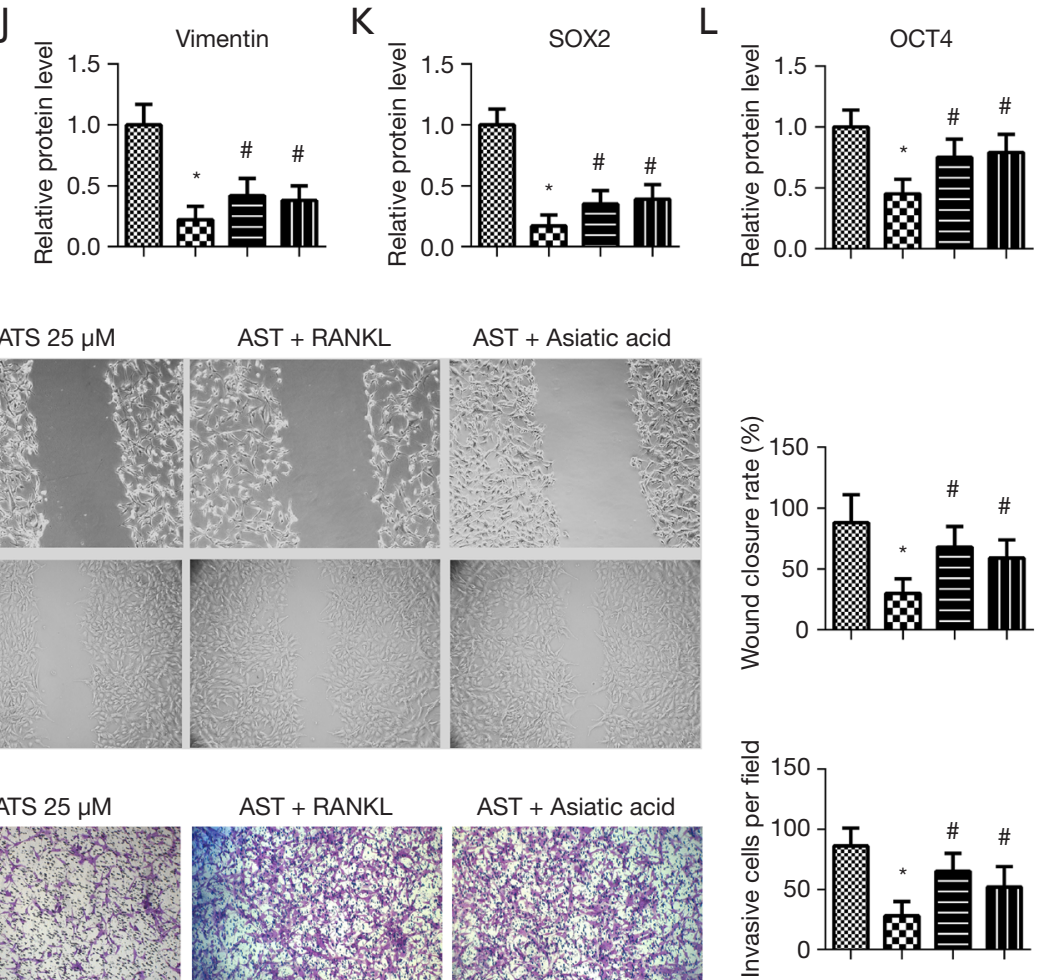

Figure 4 Effect of Asiaticoside (ATS) on the activation of p65 and p38MAPK in pancreatic cancer cell line (PANC-1) cells. Western blot detects (A) the protein expression profiles, (B) the relative expression of p-p65/p65 protein and (C) the relative expression of p-p38MAPK/ p38MAPK protein. Activators for NF-kB (RANKL, $10 \mathrm{ng} / \mathrm{mL}$ ) and MAPK (Asiatic acid, $4.6 \mathrm{mM}$ ) were added to validate their effect. (D) Cell viability were verified with CCK-8. Western blot detects (E) the protein expression profiles, and the relative expression of (F) p-p65/ p65, (G) p-P38/P38, (H) E-cadherin, (I) N-cadherin, (J) Vimentin, (K) SOX2, and (L) OCT4 were determined with Image J. (M) Wound healing of PANC-1 cells directly observed under 100x scope. (N) Invasive PANC-1 cells tested with transwell, stained with crystal violet and observed under $200 \times$ scope. Compared with $0 \mu \mathrm{mol} / \mathrm{L}$ ATS, ${ }^{*} \mathrm{P}<0.05$ versus control group; ${ }^{\#} \mathrm{P}<0.05$ versus ATS $25 \mu \mathrm{M}$ group. 
A

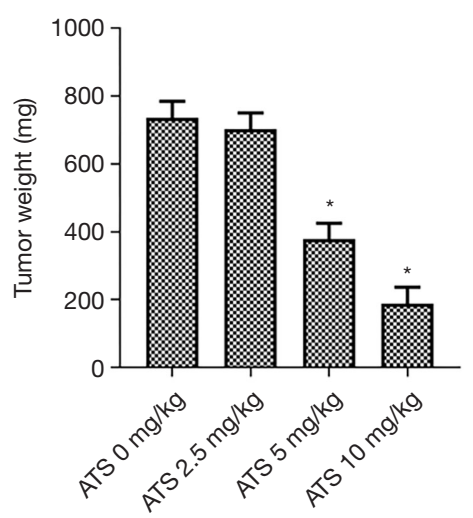

B

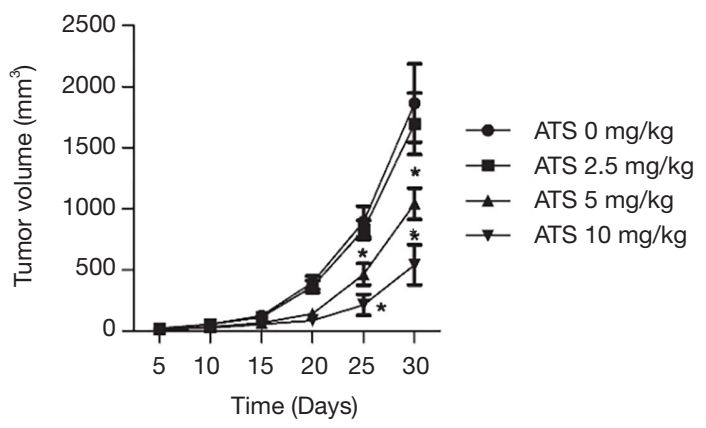

C

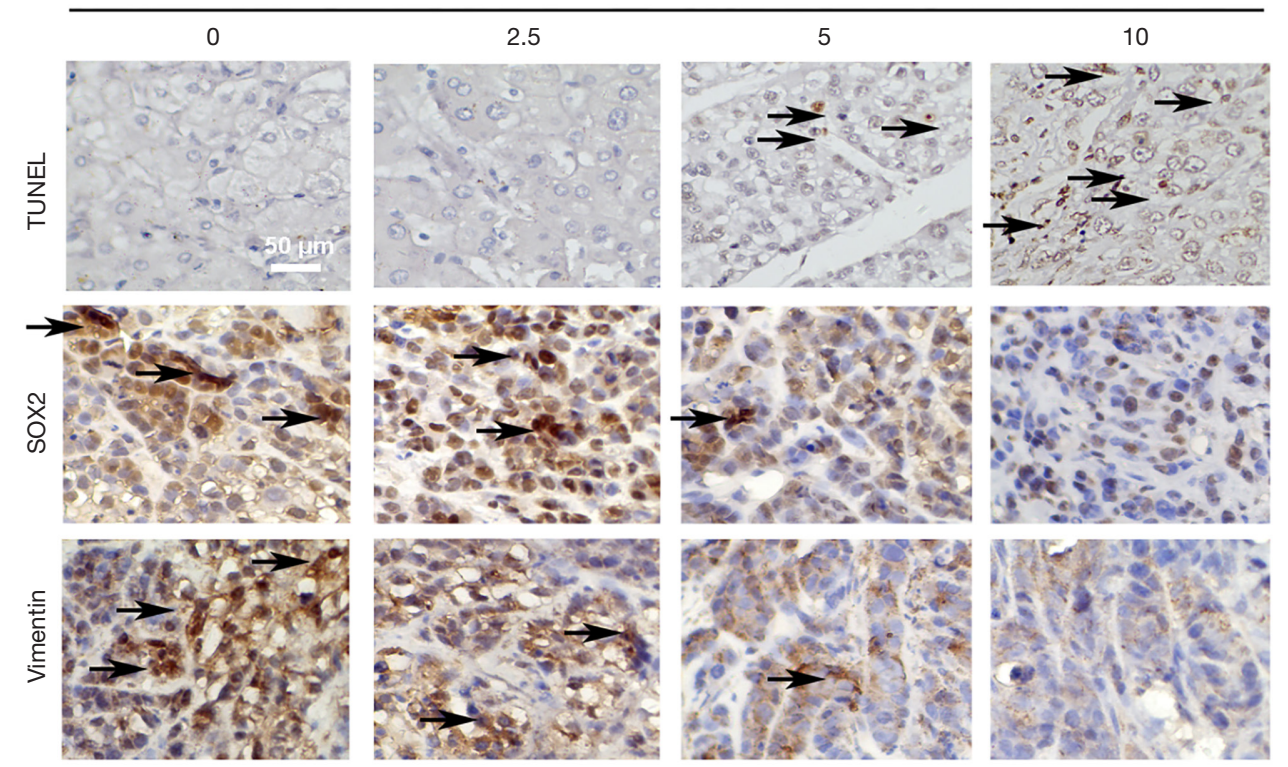

D

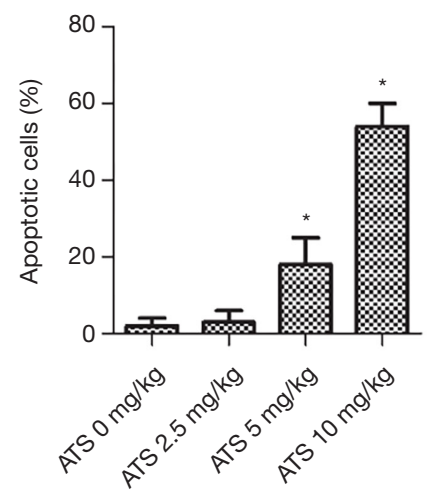

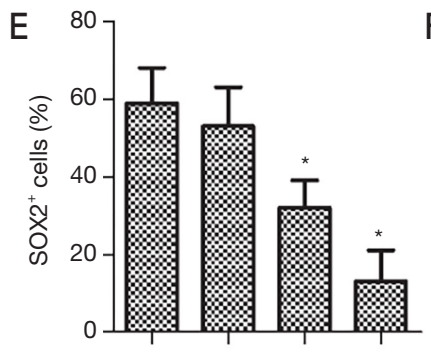

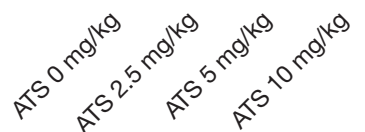

$\mathrm{F}$

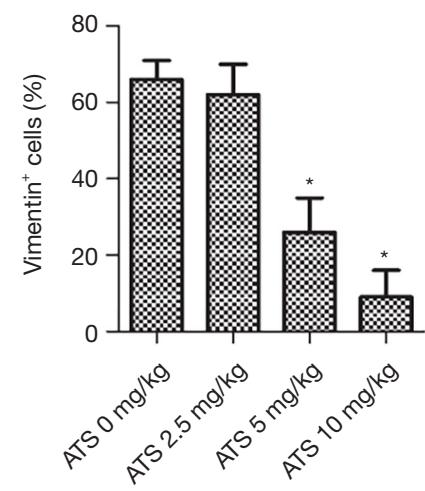

Figure 5 Effect of Asiaticoside (ATS) on the growth, apoptosis, and expression of vimentin and SOX2 protein in transplanted tumor cells in nude mice. Tumor tissue (A) weight and (B) volume. (C) The tumors were stained with TUNEL or indicated antibodies; the typically positive cells were indicated with arrows. (D) TUNEL detection of apoptosis rate in transplanted tumor cells and (E) immunohistochemical detection SOX2 positive expression rate. (F) Vimentin positive expression rate detected by immunohistochemistry; compared with $0 \mathrm{mg} / \mathrm{kg}$ ATS, ${ }^{*} \mathrm{P}<0.05$. 
Cancer stem cells were widely accepted as the main force in tumor growth, drug resistance and metastasis (15). In the adult pancreas, the differentiated pancreas cells show a high degree of plasticity, which makes it more important to inhibit cancer stem cells in pancreatic cancer treatment (16). In this study, when the ATS concentration was $25 \mu \mathrm{mol} / \mathrm{L}$, the proportion of $\mathrm{CD}_{4} 4^{+}$and CD133 positive cells decreased significantly, and the expression of SOX2 and OCT4 proteins also decreased significantly. Both CD44 and CD133 are surface markers of cancer stem cells, and have been used to identify pancreatic cancer stem cells (17). Gzil et al. showed that the expression of stem cell markers such as CD44 and CD133 is a risk factor affecting the prognosis of patients with pancreatic cancer (18). Our results suggested that ATS can reduce $\mathrm{CD} 44^{+}$and $\mathrm{CD} 133^{+}$ positive cells in a concentration-dependent manner, reduce tumor stem cells, and thus improve patient prognosis. SOX2 belongs to the Y-related HMG protein family in the SOX region, which can regulate embryonic development and is an important protein for maintaining stem cell selfrenewal and pluripotency (19). OCT4 belongs to the POU transcription factor family and plays an extremely important role in maintaining the multidifferentiation potential and self-renewal of embryonic stem cells (20). Studies have shown that SOX2 and OCT4 are initial factors for inducing cancer stem cells. Their abnormal expression is related to the occurrence of colorectal cancer, pancreatic cancer, and other tumors $(21,22)$. Our results suggested that ATS can inhibit the stem cell-like properties of PANC-1 cells in a concentration-dependent manner.

Inflammation promotes progression of tumors (23). It is suggested that inflammation in pre-malignant transformation and subsequent oncogene activation was the pivotal cause for pancreatic cancer. Then inflammation supported the formation of immune-tolerate microenvironment (24). AST was widely characterized as an anti-inflammatory agent. For example, Asiaticoside protects against cerebral ischemia-reperfusion injury in rats via inhibiting the NOD2/MAPK/NF- $\kappa \mathrm{B}$ signaling pathway (25). Also, Asiaticoside can alleviate inflammation bronchopulmonary injury induced by hypoxia in neonatal rats (26). In this study, when the ATS concentration was $25 \mu \mathrm{mol} / \mathrm{L}$, the cell's p-p65/p65 and p-p38MAPK/ p38MAPK protein expression decreased significantly. p65 belongs to the NF- $\mathrm{\kappa B}$ family, and after its activation by phosphorylation it can participate in the regulation of tumor cell proliferation, invasion, migration, and other biological behaviors (27). Marquardt et al. showed that blocking the phosphorylation of NF- $\mathrm{kB} / \mathrm{p} 65$ can upregulate the expression of E-cadherin, downregulate the expression of $\mathrm{N}$-Cadherin and vimentin, and inhibit EMT of liver cancer cells (28). Ma et al. showed that blocking the NF$\mathrm{\kappa B} / \mathrm{p} 65$ signaling pathway can also inhibit CD133+ positive stem cells (29), with our results suggesting that ATS may inhibit the phosphorylation of NF- $\mathrm{kB} / \mathrm{p} 65$ in PANC-1 cells in a concentration-dependent manner, thus inhibiting the occurrence of EMT and the stem cell-like properties of PANC-1 cells. p38MAPK belongs to the MAPK signal pathway, and its phosphorylation can promote tumor cell proliferation, invasion, and migration, thus playing an important regulatory role (28). Studies have shown that p38MAPK can regulate the phosphorylation of NF$\kappa \mathrm{B} / \mathrm{p} 65$ and the biological behavior of tumor cells (30), with our results suggesting that ATS may inhibit the phosphorylation of PANC-1 cells' p38MAPK and NF- $\mathrm{KB} /$ p65 in a concentration-dependent manner, and also inhibit the malignant biological behavior of pancreatic cancer cells.

Inflammation, EMT and stemness were mutually affecting processes in tumors $(3,15)$. Inflammation activates extracellular matrix degrading enzymes to admit immune screening, which promotes tumor growth, phenotypic switching and chemotherapy resistance. EMT, on the other hand, could activate inflammation and promote stemness. In this study, the results of tumor formation in nude mice showed that when the ATS concentration was 5 and $10 \mathrm{mg} / \mathrm{kg}$, tumor volume decreased significantly, the apoptosis rate increased significantly, and the positive expression rates of vimentin and SOX2 proteins decreased significantly, suggesting that ATS can inhibit the growth of pancreatic cancer xenografts and induce cell apoptosis in a concentration-dependent manner. Our results implicated that ATS could be a multi-targeting agent in treating pancreatic carcinoma.

In summary, ATS may block the phosphorylation of $\mathrm{p} 38 \mathrm{MAPK}$ and NF- $\mathrm{\kappa B} / \mathrm{p} 65$ in PANC-1 cells in a concentration-dependent manner, inhibiting the proliferation, EMT, and stem cell-like properties of pancreatic cancer cells and the growth of transplanted tumor cells.

\section{Acknowledgments}

Funding: None.

\section{Footnote}

Reporting Checklist: The authors have completed the 
ARRIVE reporting checklist. Available at http://dx.doi. org/10.21037/jgo-20-533

Data Sharing Statement: Available at http://dx.doi. org/10.21037/jgo-20-533

Conflicts of Interest: All authors have completed the ICMJE uniform disclosure form (available at http://dx.doi. org/10.21037/jgo-20-533). The authors have no conflicts of interest to declare.

Ethical Statement: The authors are accountable for all aspects of the work in ensuring that questions related to the accuracy or integrity of any part of the work are appropriately investigated and resolved. The in vivo experiments were carried out in Beijing Weitong Lihua Laboratory Animal Technology Co., Ltd. [SCXK (Beijing) 2016-0006] according to Chinese National Guidelines (GB/T 35892-20181).

Open Access Statement: This is an Open Access article distributed in accordance with the Creative Commons Attribution-NonCommercial-NoDerivs 4.0 International License (CC BY-NC-ND 4.0), which permits the noncommercial replication and distribution of the article with the strict proviso that no changes or edits are made and the original work is properly cited (including links to both the formal publication through the relevant DOI and the license). See: https://creativecommons.org/licenses/by-nc-nd/4.0/.

\section{References}

1. Halbrook CJ, Lyssiotis CA. Employing Metabolism to Improve the Diagnosis and Treatment of Pancreatic Cancer. Cancer Cell 2017;31:5-19.

2. Neoptolemos JP, Kleeff J, Michl P, et al. Therapeutic developments in pancreatic cancer: current and future perspectives. Nat Rev Gastroenterol Hepatol 2018;15:333-48.

3. Dongre A, Weinberg RA. New insights into the mechanisms of epithelial-mesenchymal transition and implications for cancer. Nat Rev Mol Cell Biol 2019;20:69-84.

4. Wang H, Unternaehrer JJ. Epithelial-mesenchymal Transition and Cancer Stem Cells: At the Crossroads of Differentiation and Dedifferentiation. Dev Dyn 2019;248:10-20.

5. Zhou J, Jiang YY, Wang HP, et al. Natural compound
Tan-I enhances the efficacy of Paclitaxel chemotherapy in ovarian cancer. Ann Transl Med 2020;8:752.

6. Yingchun L, Huihan W, Rong Z, et al. Antitumor Activity of Asiaticoside Against Multiple Myeloma Drug-Resistant Cancer Cells Is Mediated by Autophagy Induction, Activation of Effector Caspases, and Inhibition of Cell Migration, Invasion, and STAT-3 Signaling Pathway. Med Sci Monit 2019;25:1355-61.

7. Fitri AR, Pavasant P, Chamni S, et al. Asiaticoside induces osteogenic differentiation of human periodontal ligament cells through the Wnt pathway. J Periodontol 2018;89:596-605.

8. Juríková M, Danihel L', Polák Š, et al. Ki67, PCNA, and MCM proteins: Markers of proliferation in the diagnosis of breast cancer. Acta Histochem 2016;118:544-52.

9. Zhao J, Shi J, Shan Y, et al. Asiaticoside inhibits TGF- $\beta 1$ induced mesothelial-mesenchymal transition and oxidative stress via the Nrf2/HO-1 signaling pathway in the human peritoneal mesothelial cell line HMrSV5. Cell Mol Biol Lett 2020;25:33.

10. Nema NK, Maity N, Sarkar BK, et al. Matrix metalloproteinase, hyaluronidase and elastase inhibitory potential of standardized extract of Centella asiatica. Pharm Biol 2013;51:1182-7.

11. Coopman P, Djiane A. Adherens Junction and E-Cadherin complex regulation by epithelial polarity. Cell Mol Life Sci 2016;73:3535-53.

12. Aytac Vuruskan B, Ozturk Nazlioglu H, Vuruskan H. $\mathrm{N}$-cadherin expression in primary and metastatic testicular germ cell tumors. J buon 2018;23:1125-9.

13. Richardson AM, Havel LS, Koyen AE, et al. Vimentin Is Required for Lung Adenocarcinoma Metastasis via Heterotypic Tumor Cell-Cancer-Associated Fibroblast Interactions during Collective Invasion. Clin Cancer Res 2018;24:420-32.

14. Bulzico D, Pires BRB, DE Faria PAS, et al. Twist1 Correlates With Epithelial-Mesenchymal Transition Markers Fibronectin and Vimentin in Adrenocortical Tumors. Anticancer Res 2019;39:173-5.

15. Razi E, Radak M, Mahjoubin-Tehran M, et al. Cancer stem cells as therapeutic targets of pancreatic cancer. Fundam Clin Pharmacol 2020;34:202-12.

16. Rodriguez-Aznar E, Wiesmüller L, Sainz B, Jr., et al. EMT and Stemness-Key Players in Pancreatic Cancer Stem Cells. Cancers (Basel) 2019;11:1136.

17. Ishiwata T, Matsuda Y, Yoshimura H, et al. Pancreatic cancer stem cells: features and detection methods. Pathol Oncol Res 2018;24:797-805. 
18. Gzil A, Zarębska I, Bursiewicz W, et al. Markers of pancreatic cancer stem cells and their clinical and therapeutic implications. Mol Biol Rep 2019;46:6629-45.

19. Huang C, Lu H, Li J, et al. SOX2 regulates radioresistance in cervical cancer via the hedgehog signaling pathway. Gynecol Oncol 2018;151:533-41.

20. Cho Y, Kang HG, Kim SJ, et al. Post-translational modification of OCT4 in breast cancer tumorigenesis. Cell Death Differ 2018;25:1781-95.

21. Wahab SMR, Islam F, Gopalan V, et al. The Identifications and Clinical Implications of Cancer Stem Cells in Colorectal Cancer. Clin Colorectal Cancer 2017;16:93-102.

22. Sharma NS, Gupta VK, Dauer P, et al. O-GlcNAc modification of Sox 2 regulates self-renewal in pancreatic cancer by promoting its stability. Theranostics 2019;9:3410-24.

23. Greten FR, Grivennikov SI. Inflammation and Cancer: Triggers, Mechanisms, and Consequences. Immunity 2019;51:27-41.

24. Stone ML, Beatty GL. Cellular determinants and therapeutic implications of inflammation in pancreatic cancer. Pharmacology \& therapeutics 2019;201:202-13.

25. Zhang C, Chen S, Zhang Z, et al. Asiaticoside Alleviates Cerebral Ischemia-Reperfusion Injury via NOD2/

Cite this article as: $\mathrm{He} \mathrm{Y,} \mathrm{Peng} \mathrm{X}$, Zheng L, Tang $\mathrm{Y}, \mathrm{Li}$ J, Huang X. Asiaticoside inhibits epithelial-mesenchymal transition and stem cell-like properties of pancreatic cancer PANC-1 cells by blocking the activation of $\mathrm{p} 65$ and p38MAPK. J Gastrointest Oncol 2021;12(1):196-206. doi: 10.21037/jgo20-533
Mitogen-Activated Protein Kinase (MAPK)/Nuclear Factor kappa B (NF-кB) Signaling Pathway. Med Sci Monit 2020;26:e920325.

26. Mai LJ, Fu XX, He G, et al. Effect of asiaticoside on hyperoxia-induced bronchopulmonary dysplasia in neonatal rats and related mechanism. Zhongguo Dang Dai Er Ke Za Zhi 2020;22:71-6.

27. He F, Fan M, Jin Y, et al. Sphingosine kinase 1 inhibition decreases the epithelial-mesenchymal transition and ameliorates renal fibrosis via modulating NF- $\kappa \mathrm{B}$ signaling. Am J Transl Res 2019;11:5879-87.

28. Marquardt JU, Gomez-Quiroz L, Arreguin Camacho LO, et al. Curcumin effectively inhibits oncogenic NF- $\mathrm{NB}$ signaling and restrains stemness features in liver cancer. $\mathrm{J}$ Hepatol 2015;63:661-9.

29. Ma DQ, Zhang YH, Ding DP, et al. Effect of Bmi-1mediated NF- $\kappa \mathrm{B}$ signaling pathway on the stem-like properties of CD133+ human liver cancer cells. Cancer Biomark 2018;22:575-85.

30. Zhang N, Jiang Y, Mu F, et al. Gentiopicrin exerts antirheumatic effect in human fibroblast-like synoviocytes via inhibition of p38MAPK/NF- $\mathrm{B}$ pathway. Cell Mol Biol (Noisy-le-grand) 2019;65:85-90.

(English Language Editor: K. Brown) 